\title{
Spray Assembly of Metal-Phenolic Networks: Formation, Growth, and Applications
}

Qi-Zhi Zhong, Shuaijun Pan, Md. Arifur Rahim, Gyeongwon Yun, Jianhua Li, Yi Ju, Zhixing Lin, Yiyuan Han, Yutian Ma, Joseph J. Richardson, and Frank Caruso*

ARC Centre of Excellence in Convergent Bio-Nano Science and Technology, and the Department of Chemical Engineering, The University of Melbourne, Parkville, Victoria 3010, Australia

KEYWORDS: self-assembly, spray coating, metal-organic films, metal-phenolic networks, oil-water separation, UV shielding

\begin{abstract}
Hybrid conformal coatings - such as metal-phenolic networks (MPNs) that are constructed from the coordination-driven assembly of natural phenolic ligands - are of interest in areas including biomedicine, separation, and energy. To date, most MPN coatings have been prepared by immersing substrates in solutions containing the phenolic ligands and metal ions, which is a suitable method for coating small or flexible objects. In contrast, more industrially relevant methods for coating and patterning large substrates, such as spray assembly, have been explored to a lesser extent toward the fabrication of MPNs, particularly regarding the effect of process variables on MPN growth. Herein, a spray assembly method was used to fabricate MPN coatings with various phenolic building blocks and metal ions, and their formation and patterning were explored for different applications. Different process parameters including solvent, $\mathrm{pH}$, and metal-ligand pair allowed for control over the film properties such as
\end{abstract}


thickness and roughness. Based on these investigations, a potential route for the formation of spray-assembled MPN films was proposed. Conditions favoring the formation of bis complexes could produce thicker coatings than those favoring the formation of mono or tris complexes. Finally, the spray-assembled MPNs were used to generate superhydrophilic membranes for oil-water separation and colorless films for UV shielding. The present study provides insights into the chemistry of MPN assembly and holds promise for advancing the fabrication of multifunctional hybrid materials.

\section{INTRODUCTION}

Surface modification plays a central role in the chemical, physical, and biomedical sciences. ${ }^{1-}$

${ }^{3}$ However, simple yet versatile strategies for the surface modification of objects and interfaces are rare, as the interactions between modifiers and surfaces generally need to be tailored on a case-by-case basis. ${ }^{4-6}$ In 2013, our group reported a rapid and versatile assembly method for coating surfaces with metal-phenolic networks (MPNs) that can be composed of a wide range of phenolics and metals. ${ }^{7}$ Specifically, galloyl- and catechol-containing phenols (e.g., tannic acid (TA)) can coordinate to metal ions (e.g., $\mathrm{Fe}^{\mathrm{III}}$ ) to form thin, amorphous films on particulate and planar surfaces, ${ }^{8,9}$ endowing novel functionalities to the surfaces for potential applications in drug delivery, ${ }^{10,11}$ energy storage, ${ }^{12}$ and catalysis. ${ }^{13}$

Several methods for preparing MPN coatings have been reported to date including discrete assembly, ${ }^{7}$ coordination-driven multistep assembly, ${ }^{14}$ rust-mediated continuous assembly, ${ }^{15}$ microfluidic biphasic assembly, ${ }^{16}$ and electrotriggered assembly. ${ }^{17}$ However, these methods require the immersion of substrates in solutions of phenolics and metal ions and are thus more suitable for coating small or flexible objects (e.g., particles or fabrics). ${ }^{18-20}$ In contrast, spray coating allows for more versatility in depositing and patterning thin films on large substrates, ${ }^{21,22}$ as even entire cars can be spray coated with thin films of functional nanomaterials. ${ }^{23}$ In addition, Choi and coworkers have demonstrated that TA and Fe ${ }^{\mathrm{III}}$ ions can 
be sprayed on bulk objects (e.g., glasses and fruits) to form MPNs and explored the applications of spray-assembled MPNs including as antifouling coatings for increasing the shelf life of fruits. ${ }^{24}$ As demonstrated in previous studies, ${ }^{7,25}$ the formation of MPNs via immersive assembly methods is strongly dependent on various parameters including $\mathrm{pH}$, ligand-to-metal ratio, precursor concentration, and type of building block. ${ }^{7,15}$ In contrast, the influence of such parameters on the interfacial assembly of MPNs and the properties of the films formed via spray coating remain to be more thoroughly investigated. ${ }^{24}$ Furthermore, other potential applications of spray-assembled MPNs based on different building blocks, i.e., combinations of different phenolic ligands and metals, are yet to be explored.

Herein, we examine and establish the synthesis conditions and building blocks suitable for the spray assembly of homogenous and patterned MPNs for a variety of applications. We demonstrate that a wide toolbox of building blocks is applicable to spray assembly. We investigate the influence of key parameters $(\mathrm{pH}$, solvent, ligand-to-metal molar ratio, and precursor concentration) on the formation of the spray-assembled MPN films to determine the mechanism of film formation at the solid-liquid interface. We demonstrate the fabrication of gradient MPN coatings and Janus membranes, the formation of which has not been demonstrated to occur using immersive MPN assembly. We also demonstrate the use of the MPN coatings for endowing surfaces with superhydrophilicity for oil-water separation and UV shielding for UV protection. The present study demonstrates the benefits of spray assembly for constructing diverse MPN coatings and provides insights into the interfacial chemistry of metal-phenolic complexes.

\section{EXPERIMENTAL SECTION}

Materials. Iron(III) chloride hexahydrate $\left(\mathrm{FeCl}_{3} \cdot 6 \mathrm{H}_{2} \mathrm{O}\right)$, copper(II) chloride, aluminium(III) chloride, zirconium(IV) chloride, TA (ACS reagent, $M_{\mathrm{w}}=1701.23 \mathrm{Da}$ ), quercetin (Que), gallic acid (GA), rhodamine B (Rh B), titanium dioxide particles $(\sim 25 \mathrm{~nm})$, and polyethyleneimine 
(PEI, $M_{\mathrm{w}}=\sim 25000 \mathrm{Da}$ ) were purchased from Sigma-Aldrich. $N, N$-dimethylformamide (DMF), dimethyl sulfoxide (DMSO), methanol $(\mathrm{MeOH})$, acetonitrile, ethanol (EtOH), 2-propanol, acetone, $n$-hexane, toluene, petroleum ether, sodium chloride, and hydrochloric acid and sodium hydroxide (used for adjusting the $\mathrm{pH}$ of the precursor solutions) were purchased from Chem-Supply and used without further purification. Quartz plates were purchased from ProSciTech (Australia). Silicon wafers were purchased from MMRC Pty. Ltd. Polypropylene membranes were purchased from Sterlitech Corporation. Natural rubber was purchased from Mediflex Industries Pty. Ltd. Iron plates, polycarbonate, polystyrene, and polyurethane sponge were purchased from Shengjili Pty. Ltd. High-purity (Milli-Q) water with a resistivity of 18.2 $\mathrm{M} \Omega \mathrm{cm}$ was obtained from an inline Millipore RiOs/Origin water purification system.

Characterization. UV-visible (UV-vis) absorption spectra were measured on a Varian Cary $4000 \mathrm{UV}-\mathrm{vis}$ spectrophotometer. Atomic force microscopy (AFM) experiments were performed on a JPK NanoWizard II BioAFM instrument. The thickness of the coatings was measured using an Auto SE spectroscopic ellipsometer (Horiba Jobin Yvon). Contact angle measurements were performed on a Data Physics OCA 20 tensiometer and recorded with OCA software using the sessile drop profile. All thickness and contact angle measurements were performed at more than five different spots for each sample, and the average value was reported. The error bars represent the standard deviation of the five measurements performed. Attenuated total reflectance Fourier transform infrared spectroscopy (ATR-FTIR) analysis was carried out on a Varian 7000 FTIR spectrometer (Bruker). X-ray photoelectron spectroscopy (XPS) spectra were collected using a VGESCALAB220i-XL spectrometer equipped with a monochromated $\mathrm{Al} \mathrm{K} \alpha \mathrm{X}$-ray source $(1486.6 \mathrm{eV}$ at $10 \mathrm{kV}$ and $12 \mathrm{~mA})$. Scanning electron microscopy (SEM) images and energy-dispersive X-ray spectroscopy (EDX) profiles were acquired by an FEI Teneo VolumeScope instrument. Dynamic light scattering measurements were carried out in water at $\mathrm{pH} 11$ by using a Zetasizer Nano ZS (Malvern). 
Preparation of Substrates. Quartz slides and silicon wafers were cut into pieces of roughly $2 \mathrm{~cm} \times 2 \mathrm{~cm}$ and used as substrates. Before coating, the substrates were cleaned with piranha solution $\left(30 \% \mathrm{H}_{2} \mathrm{O}_{2} / 98 \% \mathrm{H}_{2} \mathrm{SO}_{4}, 1: 3 \mathrm{v} / \mathrm{v}\right)$ for $5 \mathrm{~min}$, rinsed with copious amount of Milli-Q water, and dried under a stream of air. Caution! Piranha solution reacts violently with organic material and should be handled carefully. The clean substrates were then immersed in a PEI solution ( $\left.1 \mathrm{mg} \mathrm{mL}^{-1}, 0.5 \mathrm{M} \mathrm{NaCl}\right)$ for $30 \mathrm{~min}$, rinsed in Milli-Q water three times, and dried under a stream of air before use. Polycarbonate, polystyrene, and polyurethane sponges were cleaned ultrasonically in 2-propanol for $15 \mathrm{~min}$ before use. Polypropylene membranes were washed with acetone for $4 \mathrm{~h}$ and then dried at $80{ }^{\circ} \mathrm{C}$ to a constant weight before use.

Preparation of TA-Fe ${ }^{\mathrm{III}}$ Coating on Substrates by Spray Coating. Aqueous solutions of TA $\left(2.0 \mathrm{mg} \mathrm{mL}{ }^{-1}\right)$ and $\mathrm{FeCl}_{3} \cdot 6 \mathrm{H}_{2} \mathrm{O}\left(0.5 \mathrm{mg} \mathrm{mL}^{-1}\right)$ from $100 \mathrm{~mL}$ plastic bottles (trigger equipped) were deposited sequentially on the substrates by a single pull of the spray trigger (the volume solution in each spray step was $0.3 \mathrm{~mL}$, which covered an area of $64 \mathrm{~cm}^{2}$ ). The distance from the spray nozzle to the substrate was $8 \mathrm{~cm}$, and the solutions were sprayed horizontally and at an angle perpendicular to the plane of the substrate. Specifically, TA solution was first sprayed onto the substrate and allowed to stand for $20 \mathrm{~s}$, followed by spraying of $\mathrm{FeCl}_{3} \cdot 6 \mathrm{H}_{2} \mathrm{O}$ solution. The latter was also allowed to stand on the previously sprayed TA solution layer for $20 \mathrm{~s}$. The excess sprayed solution was washed with Milli-Q water, and the coated substrate was dried under a stream of air. This procedure is referred to as one cycle of spray coating. A similar protocol was used with phenolic solutions of different $\mathrm{pHs}$ to investigate the effects of $\mathrm{pH}$ on the coating properties, while the $\mathrm{pH}$ of $\mathrm{FeCl}_{3} \cdot 6 \mathrm{H}_{2} \mathrm{O}$ solution was kept at 2.5. The same protocol was also used for the different solvents examined, except that the washing solution was ethanol. To investigate the effect of ligand-to-metal (precursor) molar ratio, the concentration of TA was fixed at $2 \mathrm{mg} \mathrm{mL}^{-1}(1.2 \mathrm{mM})$, while the concentration of $\mathrm{FeCl}_{3} \cdot 6 \mathrm{H}_{2} \mathrm{O}$ was varied from 1.2 to $6.0 \mathrm{mM}$. To investigate the effect of precursor 
concentration, the TA: $\mathrm{FeCl}_{3} \cdot 6 \mathrm{H}_{2} \mathrm{O}$ molar ratio was fixed at $1: 1.5$, while the concentration of TA was varied from 0.3 to $4.8 \mathrm{mM}$. To investigate the effect of ionic strength, the concentrations of TA and $\mathrm{FeCl}_{3} \cdot 6 \mathrm{H}_{2} \mathrm{O}$ were fixed at $2 \mathrm{mg} \mathrm{mL}^{-1}$ and $0.5 \mathrm{mg} \mathrm{mL}^{-1}$, respectively, while the concentration of sodium chloride in TA and $\mathrm{FeCl}_{3} \cdot 6 \mathrm{H}_{2} \mathrm{O}$ solutions was $1 \mathrm{M}$.

\section{Preparation of Spray-Assembled MPNs with Different Metals and Phenolic Ligands.}

For the assembly of MPNs constituting different metals and phenolic ligands, the concentration of the phenolic solution investigated was $2.0 \mathrm{mg} \mathrm{mL}^{-1}$ and that of the metal ion solution examined was $0.5 \mathrm{mg} \mathrm{mL}{ }^{-1}$. To prepare the TA-Cu${ }^{\mathrm{II}}-\mathrm{Al}^{\mathrm{III}}-\mathrm{Zr}^{\mathrm{IV}}$ coatings, the concentration of TA was $2.0 \mathrm{mg} \mathrm{mL}^{-1}$, and the concentrations of $\mathrm{Cu}^{\mathrm{II}}, \mathrm{Al}^{\mathrm{III}}$, and $\mathrm{Zr}^{\mathrm{IV}}$ were $0.5 \mathrm{mg} \mathrm{mL}^{-1}$. To prepare the GA-Que-Fe ${ }^{\mathrm{III}}$ coatings, the concentrations of GA and Que were $2.0 \mathrm{mg} \mathrm{mL}^{-1}$ and that of $\mathrm{Fe}^{\mathrm{III}}$ was $0.5 \mathrm{mg} \mathrm{mL}^{-1}$. The phenolic solution was first sprayed onto the substrate and allowed to stand for $20 \mathrm{~s}$, followed by spraying of the metal solution and subsequent standing for $20 \mathrm{~s}$. The substrate was then washed and dried to obtain the MPN coatings.

Preparation of Gradient MPN Coatings. Natural rubber samples were cut into pieces (roughly $1.5 \mathrm{~cm} \times 10 \mathrm{~cm}$ ) and cleaned with Milli-Q water before use. The concentrations of TA and $\mathrm{FeCl}_{3} \cdot 6 \mathrm{H}_{2} \mathrm{O}$ solutions were 10 and $2.5 \mathrm{mg} \mathrm{mL}^{-1}$ (both in ethanol), respectively. A polycarbonate (PC) sheet was used as a "cover". The PC cover was initially placed at the 8-cm mark at the right end of the substrate (rubber). TA solution was then sprayed onto the uncovered substrate area and allowed to stand for $10 \mathrm{~s}$, after which $\mathrm{FeCl}_{3} \cdot 6 \mathrm{H}_{2} \mathrm{O}$ solution was sprayed and subsequently allowed to stand for $10 \mathrm{~s}$. The PC cover was then moved to the 6-cm mark, subsequently to the 4-cm mark, 2-cm mark, and the 0 -cm mark, with the spray coating process repeated between each displacement. A total of 25 (spraying) cycles ( 5 at each mask position) were performed to fabricate the gradient coating. The coated substrate (rubber) was then washed with ethanol and dried under a stream of air. 
Preparation of Janus MPN Coatings. Polypropylene membranes were cleaned as mentioned above. The concentration of TA and $\mathrm{FeCl}_{3} \cdot 6 \mathrm{H}_{2} \mathrm{O}$ solutions were 10 and $2.5 \mathrm{mg} \mathrm{mL}^{-}$ ${ }^{1}$ (both in ethanol), respectively. TA solution was first sprayed on a polypropylene membrane and allowed to stand for $20 \mathrm{~s}$. The $\mathrm{FeCl}_{3} \cdot 6 \mathrm{H}_{2} \mathrm{O}$ solution was then sprayed and allowed to stand for 20 s. Subsequently, excess sprayed solution was washed off by ethanol. After 20 spraying/washing cycles, the coated polypropylene membrane was rinsed with ethanol and dried at $80^{\circ} \mathrm{C}$. Contact angle and FTIR measurements were then performed.

Oil-Water Separation. For this application, both sides of a polypropylene membrane were sprayed with TA and $\mathrm{Fe}^{\mathrm{III}}$ solutions for 20 cycles. The concentrations of TA and $\mathrm{FeCl}_{3} \cdot 6 \mathrm{H}_{2} \mathrm{O}$ solutions were 10 and $2.5 \mathrm{mg} \mathrm{mL}^{-1}$ (both in ethanol), respectively. The separation experiments were performed using an in-house filtration unit, and the coated membrane was placed in the middle of the unit. Oil/water mixtures $(1: 1 \mathrm{v} / \mathrm{v})$ were poured from the top of the unit, and separation, which was achieved by gravity, was evaluated. For each oil/water mixture, the separation experiments were performed three times, and the average value was reported. The error bars represent the standard deviation of the three measurements performed.

UV Shielding. To assess the UV-shielding performance of the coatings, the degradation of $\mathrm{Rh}$ B solution containing $\mathrm{TiO}_{2}$ nanoparticles under UV radiation (Nelson UV lamp, $20 \mathrm{~W}$ ) was examined. Briefly, $20 \mathrm{mg}$ of $\mathrm{TiO}_{2}$ and $20 \mathrm{~mL}$ of $0.01 \mathrm{mg} \mathrm{mL}^{-1} \mathrm{Rh}$ B solution were mixed in a beaker and allowed to stir throughout the entire experiment. A colorless $\mathrm{TA}-\mathrm{Zr}^{\mathrm{IV}}$ coating on a quartz slide was used to cover the mouth of the beaker before UV irradiation. The distance between the lamp and the $\mathrm{TA}-\mathrm{Zr}^{\mathrm{IV}}$-coated quartz was $3 \mathrm{~cm}$. At given time intervals, $2 \mathrm{~mL}$ of the reaction mixture was collected, centrifuged $(3000 \mathrm{~g}, 5 \mathrm{~min})$ to remove the $\mathrm{TiO}_{2}$ nanoparticles, and the change in absorbance of $\mathrm{Rh} B$ at $552 \mathrm{~nm}$ was monitored using a UV-vis spectrophotometer.

\section{RESULTS AND DISCUSSION}


Spray Assembly of Diverse MPN Coatings. The general method for spray assembly used in the present study is schematically presented in Figure 1a. A polyphenol (e.g., TA) solution was first sprayed onto the substrate, followed by spraying with a metal ion (e.g., Fe ${ }^{\mathrm{III}}$ ) solution. The process was repeated accordingly to increase the film thickness in discrete increments, which could be monitored by UV-vis spectroscopy. As observed in Figure 1b, the ligand-tometal charge transfer (LMCT) band characteristic of TA-Fe ${ }^{\mathrm{III}}$ coordination interactions (565 $\mathrm{nm}$, dominant bis-type complexation) increased linearly with the number of spray cycle. ${ }^{14,26}$ Ellipsometric measurements confirmed that the thickness grew linearly at about $2.5 \mathrm{~nm}$ per cycle (Figure 1c), which is consistent with the literature. ${ }^{24}$ AFM measurements demonstrated that the root-mean-square $(\mathrm{rms})$ roughness of the TA-Fe ${ }^{\mathrm{III}}$ coatings (with a thickness of $\sim 15$ $\mathrm{nm}$ ) was relatively smooth at $2.9 \mathrm{~nm}$ (Figure S1, Supporting Information). Moreover, XPS analysis of the coatings revealed an $\mathrm{Fe} 2 \mathrm{p}_{3 / 2}$ signal at $\sim 712 \mathrm{eV}$ with a $2 \mathrm{p}$ peak separation of $\sim 14 \mathrm{eV}$, suggesting that $\mathrm{Fe}^{\mathrm{III}}$ was the dominant species in the coatings (Figure S2). ${ }^{15}$ From the O 1s XPS spectra, the peak appearing at $\sim 533.5 \mathrm{eV}$ could be assigned to $\mathrm{O}-\mathrm{C}$ of TA and $\mathrm{O}-$ Fe, whereas the peak at $531.8 \mathrm{eV}$ could be attributed to $\mathrm{O}=\mathrm{C}$ of TA and $\mathrm{O}-\mathrm{Fe} .{ }^{27,28}$ 

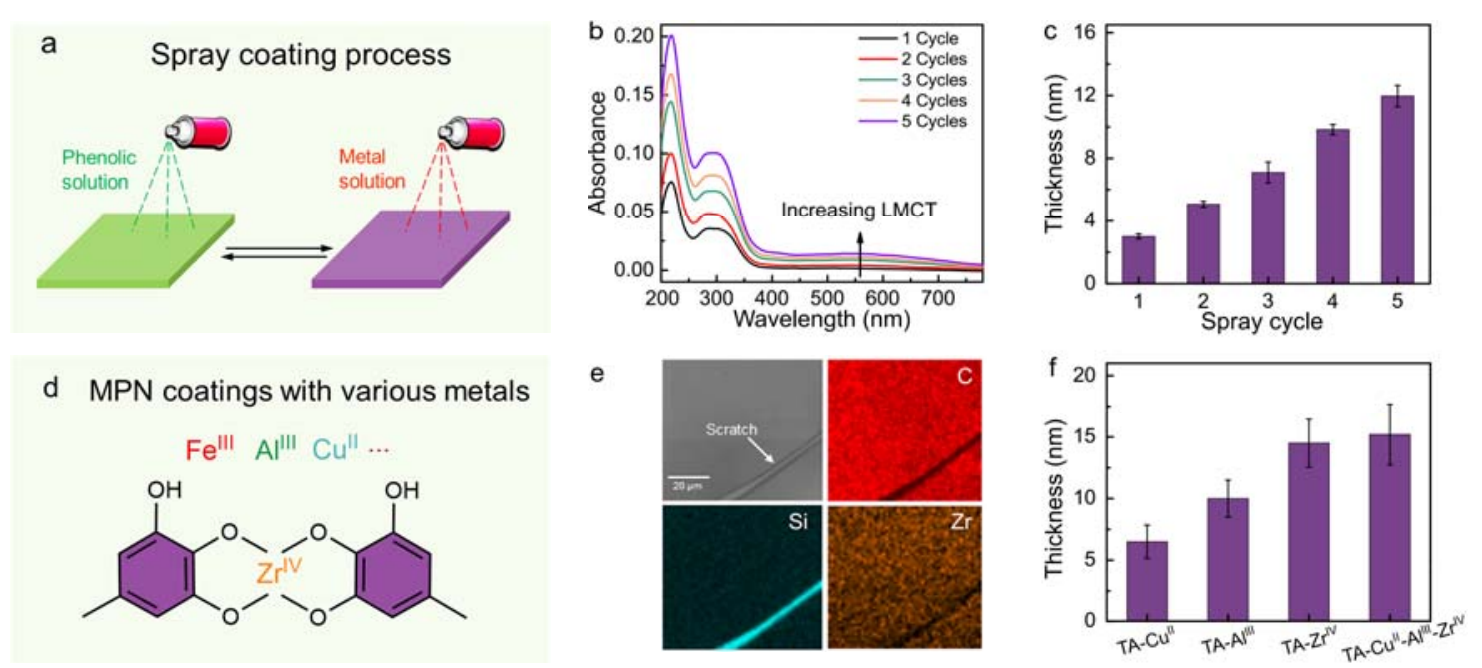

g MPN coatings with various phenols
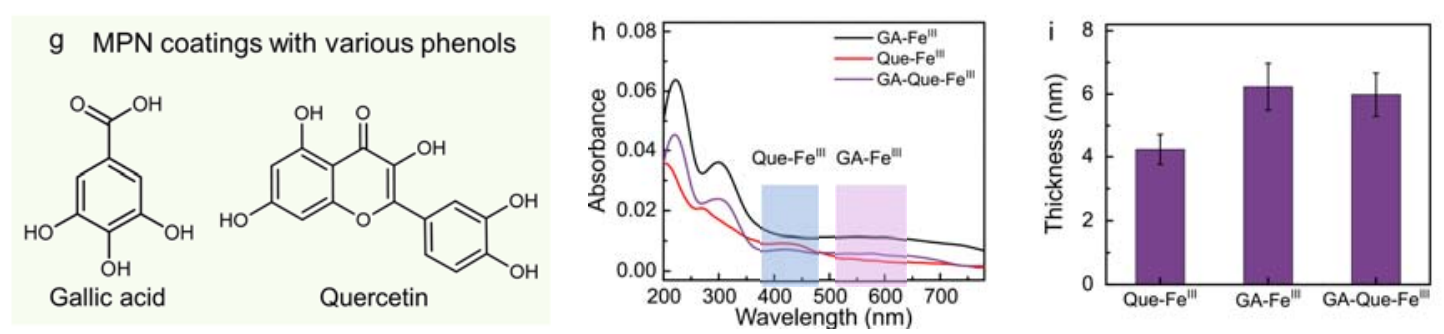

Figure 1. Structural tailorability of MPN coatings via spray assembly. Spray coating process:

(a) solutions of phenolic ligands and metals were alternately sprayed onto a substrate with washing and drying steps after the metal solution spraying; and (b) UV-vis absorption spectra and (c) corresponding thickness profiles of the TA-Fe ${ }^{\mathrm{III}}$ coatings obtained as a function of cycle number. MPN coatings with various metals: (d) schematic structure of MPNs with various metal ions; (e) SEM (top left corner) and EDX images showing $\mathrm{C}$ and $\mathrm{Zr}$ in the $\mathrm{TA}-\mathrm{Zr}{ }^{\mathrm{IV}}$ coatings (a scratch was made to reveal the quartz substrate (Si)); and (f) metal ion-dependent thickness profiles of MPN coatings after 5 spray cycles. MPN coatings with various phenolics: (g) molecular structures of gallic acid (GA) and quercetin (Que); and (h) UV-vis absorption spectra of MPN coatings composed of different ligands after 5 spray cycles and (i) the corresponding thickness profiles.

Similarly to immersive MPN assembly, the spray assembly process examined herein was versatile and applicable to diverse metal ions $\left(\mathrm{Cu}^{\mathrm{II}}, \mathrm{Al}^{\mathrm{III}}\right.$, and $\left.\mathrm{Zr}^{\mathrm{IV}}\right)$. The EDX mapping images revealed the successful formation of $\mathrm{TA}-\mathrm{Cu}^{\mathrm{II}}$, $\mathrm{TA}-\mathrm{Al}^{\mathrm{III}}$, and $\mathrm{TA}-\mathrm{Zr}^{\mathrm{IV}}$ coatings on the silicon 
wafer (Figure S3 and Figure 1e). After 5 spray cycles, the thicknesses of the TA-Cu${ }^{\mathrm{II}}, \mathrm{TA}-\mathrm{Al}{ }^{\mathrm{III}}$, and $\mathrm{TA}-\mathrm{Zr}^{\mathrm{IV}}$ coatings were $6.5 \pm 1.3,10.2 \pm 1.4$, and $14.3 \pm 1.9 \mathrm{~nm}$ (Figure 1f), respectively. The spray assembly method also allowed for the facile fabrication of multimetallic MPN coatings (Figure $\mathrm{S} 3 \mathrm{e}-\mathrm{h}$ ) using mixed metal solutions; the $\mathrm{TA}-\mathrm{Cu}^{\mathrm{II}}-\mathrm{Al}^{\mathrm{III}}-\mathrm{Zr}^{\mathrm{IV}}$ coatings had a thickness of $15.2 \pm 2.4 \mathrm{~nm}$ (Figure 1f). Additionally, the metal influenced the roughness of films formed using the spray assembly process. For instance, the degree of roughness of the TA-Al ${ }^{\mathrm{III}}$ coatings at a film thickness of $\sim 15 \mathrm{~nm}(1.5 \mathrm{~nm})$ was half of that of the TA-Fe ${ }^{\mathrm{III}}$ coatings at the same film thickness (Figure S4).

Different phenolic ligands (GA, Que, and a combination of GA and Que) were also successfully used to fabricate single- and multiligand MPNs. Figure $1 \mathrm{~h}$ shows the UV-vis absorption spectra of Fe ${ }^{\mathrm{III}}$-based MPN coatings with GA and/or Que. The absorbance at 436 $\mathrm{nm}$ could be assigned to the extension of the conjugated $\pi$-system of Que-Fe $\mathrm{e}^{\mathrm{III}}$ and the band at $565 \mathrm{~nm}$ was assigned to the LMCT band of GA-Fe ${ }^{\mathrm{III}},{ }^{26,29}$ confirming the formation of Que$\mathrm{Fe}^{\mathrm{III}}, \mathrm{GA}-\mathrm{Fe}^{\mathrm{III}}$, and multiligand GA-Que-Fe ${ }^{\mathrm{III}}$ coatings via spray assembly. It is worth noting that Que is a water insoluble phenolic ligand (Figure S5) but can be dissolved in ethanol and sprayed to form MPN coatings with $\mathrm{Fe}^{\mathrm{III}}$ ions. Diverse material surfaces, that is metallic $(\mathrm{Fe})$, oxide $\left(\mathrm{SiO}_{2}\right)$, and polymeric substrates (polystyrene, polypropylene, polyurethane), could be coated with Que-Fe ${ }^{\mathrm{III}}$ (Figure S6), highlighting that the adhesion of spray-assembled Que-Fe $\mathrm{III}^{\mathrm{II}}$ coatings is as surface-independent as the adhesion of spray-assembled TA-based MPN coatings. After 5 cycles, the thickness of the Que-Fe ${ }^{\mathrm{III}}, \mathrm{GA}-\mathrm{Fe}^{\mathrm{III}}$, and GA-Que-Fe ${ }^{\mathrm{III}}$ coatings were $4.2 \pm$ $0.6,6.7 \pm 0.7$, and $6.1 \pm 0.6 \mathrm{~nm}$ (Figure 1i), respectively. The GA-Fe ${ }^{\mathrm{III}}$ coatings (with a thickness of $\sim 15 \mathrm{~nm}$ ) showed an rms roughness value of $2.7 \mathrm{~nm}$ (Figure $\mathrm{S} 7$ ), which was comparable with that of the TA-Fe ${ }^{\mathrm{III}}$ coatings $(2.9 \mathrm{~nm})$. The observed differences in the physical characteristics (e.g., thickness and roughness) of the spray-assembled MPN coatings prepared from different phenolic ligands can likely be attributed to their size and structural 
differences of the ligands used. The aforementioned experiments highlight that a range of phenolic and metal ion building blocks can be incorporated into MPN coatings via spray assembly.

\section{Factors Influencing the Formation and Growth of Spray-Assembled MPNs. To} understand the formation and growth behavior of the MPN coatings during spray assembly, different factors relating to the assembly conditions including $\mathrm{pH}$, solvent, and precursor molar ratio and concentration were investigated using $\mathrm{TA}-\mathrm{Fe}^{\mathrm{III}}$ as a model system. Considering the pH-dependent coordination modes (i.e., mono, bis and tris complexes) ${ }^{30,31}$ of TA-Fe ${ }^{\mathrm{III}}$, the influence of $\mathrm{pH}$ on the spray assembly was studied first (pH 1-11). The $\mathrm{pH}$ of the Fe $\mathrm{FII}^{\mathrm{III}}$ solution was maintained at 2.5 , as higher pHs would instigate the formation of insoluble iron hydroxide species,${ }^{14}$ while the $\mathrm{pH}$ of the TA solution was changed accordingly to control the final $\mathrm{pH}$ of the mixed solution. Although the LMCT bands of the complexes in solution were $\mathrm{pH}$ dependent, the LMCT bands relating to the coatings prepared appeared at $540-570 \mathrm{~nm}$ regardless of the $\mathrm{pH}$ studied, indicating that bis complexes ${ }^{30,31}$ were most likely the dominant coordination species in the sprayed coatings regardless of the solution $\mathrm{pH}$ (Figure $2 \mathrm{a}$ and Figures S8 and S9).

On the basis of the findings discussed above, the following mechanism for the formation of the spray-assembled MPN coatings is proposed. At pH 1 (Scheme 1, case I), only mono complex formation is favorable, which indicates a lack of sufficient crosslinking for the formation of networks, and the thickness of the coatings was comparable with the molecular size of TA $(\sim 1.5 \mathrm{~nm}$, Figure 2b). In the range of $\mathrm{pH} 3-7$ (Scheme 1, case II), the thicknesses of the TA-Fe ${ }^{\mathrm{III}}$ coatings were relatively similar, between $11.9 \pm 0.7$ to $13.8 \pm 0.3 \mathrm{~nm}$, and the LMCT bands appeared at around $565 \mathrm{~nm}$. TA molecules first adhere to the substrate after the initial TA solution spray. Subsequent spraying of the Fe $\mathrm{F}^{\mathrm{III}}$ ions instigates both lateral and longitudinal crosslinking of the TA molecules. Moreover, the bis complexes formed in the 
liquid layer can further bind to the pre-absorbed TA-Fe ${ }^{\mathrm{III}}$ layer, leading to the growth of thicker coatings (Figure S10). However, the formation of tris-type complexes was unlikely owing to steric hindrance and unfavorable $\mathrm{pH} .{ }^{14}$ When the $\mathrm{pH}$ was raised to 11 (Scheme 1, case III), the thickness decreased to $7.2 \pm 0.6 \mathrm{~nm}$. Although the LMCT bands did not appear at $510 \mathrm{~nm}$ (typical absorption peak for tris complexes), ${ }^{32,33}$ they shifted from 560 to $540 \mathrm{~nm}$ at $\mathrm{pH} 11$, and the ratio of absorption at $510 \mathrm{~nm}$ to that at $565 \mathrm{~nm}$ increased as well, indicating the presence of tris complexes in the coatings (Figure 2a). A high $\mathrm{pH}$ can lead to the formation of tris complexes and oxidative polymerization of TA in the liquid layer (Figure S11), ${ }^{34}$ resulting in the increased rms roughness $(5.1 \mathrm{~nm}$ at $\mathrm{pH} \mathrm{11}$, Figure S12) and a reduced films thickness, as the diffusion of these large complexes to the substrate surface may be restricted. ${ }^{33}$ Additionally, the galloyl groups in TA molecules can be oxidized to quinone groups at high $\mathrm{pH}$ values, which may result in reduced adhesion to the substrate. ${ }^{35-37}$ Therefore, we postulate that few tris complexes can adhere to the pre-absorbed TA-Fe ${ }^{\mathrm{III}}$ layer, and thus bis-type TA-Fe ${ }^{\mathrm{III}}$ complexes remain the dominant coordination species in the coatings across the $\mathrm{pH}$ range studied.
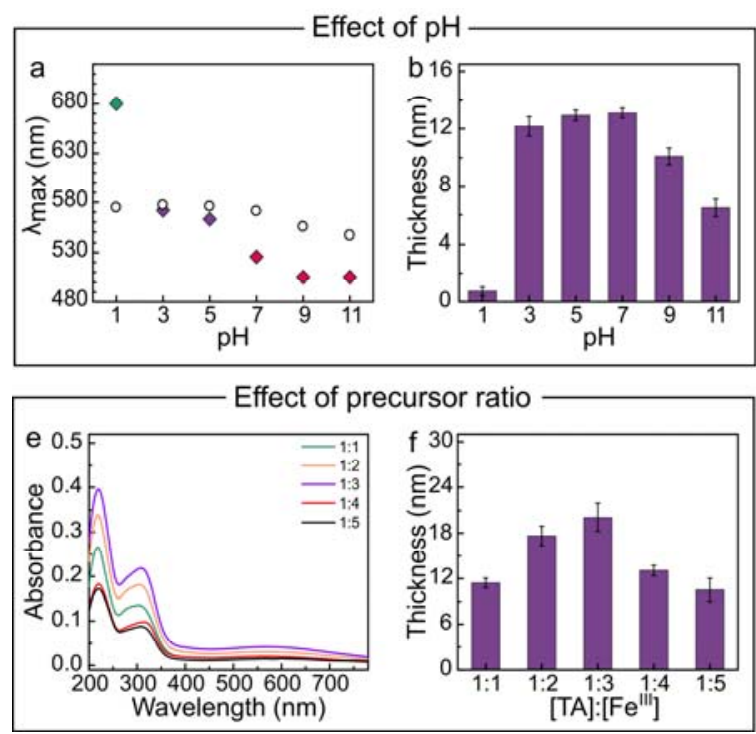
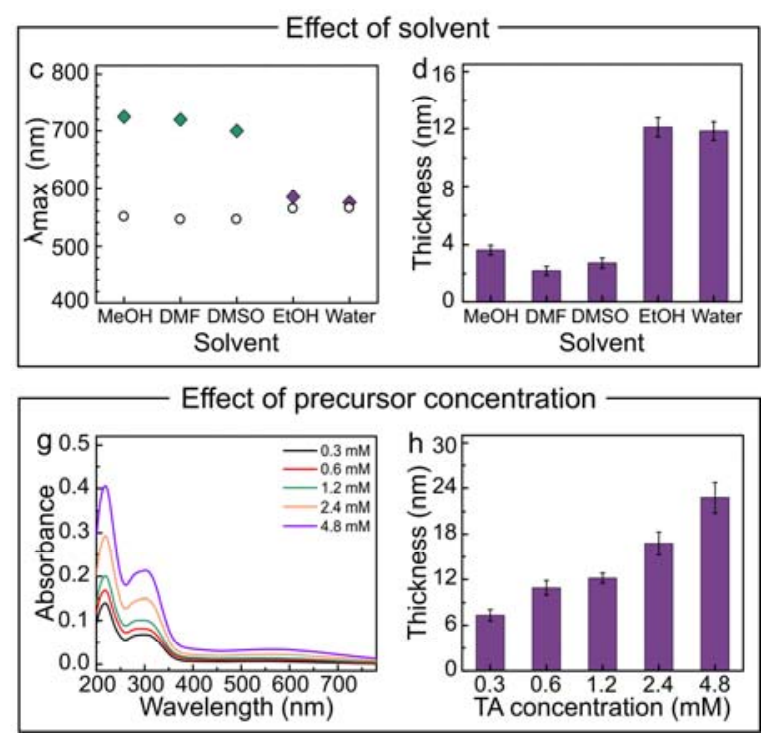

Figure 2. Factors influencing the formation and growth of TA-Fe ${ }^{\mathrm{III}}$ coatings. Effect of pH: (a) LMCT bands of TA-Fe $\mathrm{III}^{\mathrm{III}}$ complexes formed at various $\mathrm{pH}$ values in solutions (rhombuses) and coatings (open circles) and (b) thickness profiles of the TA-Fe ${ }^{\mathrm{III}}$ coatings after 5 spray cycles 
prepared at varying pHs. Effect of solvent: (c) LMCT bands of TA-Fe ${ }^{\mathrm{III}}$ complexes formed in various solvents (rhombuses) and coatings (open circles) and (d) corresponding thickness profiles of the TA-Fe ${ }^{\mathrm{III}}$ coatings after 5 spray cycles. Effect of precursor ratio: (e) UV-vis absorption spectra of the TA-Fe ${ }^{\mathrm{III}}$ coatings prepared from different precursor molar ratios (the TA concentration was fixed at $1.2 \mathrm{mM}$ ) and (f) corresponding thickness profiles of the TA$\mathrm{Fe}^{\mathrm{III}}$ coatings after 5 spray cycles. Effect of precursor concentration: (g) UV-vis absorption spectra of the TA-Fe ${ }^{\mathrm{III}}$ coatings prepared at different precursor concentrations (the $[\mathrm{TA}]:\left[\mathrm{Fe}^{\mathrm{III}}\right]$ molar ratio was fixed at $1: 1.5)$ and (h) corresponding thickness profiles of the TA-Fe ${ }^{\mathrm{III}}$ coatings after 5 spray cycles. $\mathrm{MeOH}$, methanol; DMF, $N, N$-dimethylformamide; DMSO, dimethyl sulfoxide; EtOH, ethanol.

We then investigated the effect of different solvents on the spray assembly of TA-Fe ${ }^{\mathrm{III}}$ coatings. The TA-Fe ${ }^{I I I}$ complexes formed in different solvents displayed different colors, likely due to different coordination states. ${ }^{38,39}$ For example, the complexes were green in $\mathrm{MeOH}$, DMF, and DMSO, and blue-purple in EtOH and water (Figure S13). The LMCT bands of TA$\mathrm{Fe}^{\mathrm{III}}$ in $\mathrm{MeOH}, \mathrm{DMF}$, and DMSO appeared at around $700 \mathrm{~nm}$ (Figure 2c and Figure S14), indicating dominant mono complexes in solution. In EtOH and water, the LMCT bands were observed at around $565 \mathrm{~nm}$, suggesting that bis complexes were dominant in solution. ${ }^{39} \mathrm{In}$ contrast, despite the different complex states in solution, the corresponding TA-Fe ${ }^{\mathrm{III}}$ coatings all showed an LMCT band at around $565 \mathrm{~nm}$ (Figure 2c and Figure S15), suggesting that bis complexes were the dominant complex in the coatings. Figure $2 \mathrm{~d}$ shows that the TA-Fe $\mathrm{III}^{\mathrm{II}}$ coatings prepared from $\mathrm{MeOH}, \mathrm{DMF}$, and DMSO achieved a thickness of $\sim 3 \mathrm{~nm}$ after 5 spray cycles. In contrast, the coatings prepared in EtOH and water (bis complex) were thicker $(\sim 12$ $\mathrm{nm})$. Therefore, combined with the results observed on the effect of $\mathrm{pH}$, it can be concluded that conditions favoring bis complex formation produce thicker MPN coatings. 
The influences of the precursor (ligand-to-metal) molar ratio and concentration on the formation of the TA-Fe ${ }^{\mathrm{III}}$ coatings were also examined. To study the effect of the precursor molar ratio, the TA concentration was fixed at $1.2 \mathrm{mM}$ and the $\mathrm{Fe}^{\mathrm{III}}$ concentration was varied from 1.2 to $6.0 \mathrm{mM}$. Irrespective of the TA:Fe ${ }^{\mathrm{III}}$ ratio, bis complexes remained the dominant species in the coatings (Figure 2e), as assessed from the LMCT band position. The thickness of the coatings initially increased as the molar ratio increased, reaching a maximum of $20 \pm 1.8$ $\mathrm{nm}$ at 1:3 before decreasing with further increases in molar ratio. Thus, a molar ratio of 1:3 was established to be the optimal ratio for constructing thick coatings.

To examine the effect of precursor concentration, the TA:Fe ${ }^{\mathrm{III}}$ ratio was fixed at 1:1.5, while the TA concentration was varied from 0.3 to $4.8 \mathrm{mM}$. As observed in Figure $2 \mathrm{~h}$, the thickness of the coatings increased from $8.2 \pm 0.7$ to $22.5 \pm 1.9 \mathrm{~nm}$ as the TA concentration increased from 0.3 to $4.8 \mathrm{mM}$. The effect of ionic strength on the spray formation of TA-Fe $\mathrm{e}^{\mathrm{III}}$ films was also examined, where an increase in ionic strength led to thicker and rougher MPN coatings (Figure S16), which is consistent with our previous study on the formation of TA-Fe ${ }^{\mathrm{III}}$ films by discrete deposition. ${ }^{40}$ On the basis of the above observations, it can be concluded that the physicochemical properties (thickness and complex coordination state) of the MPN coatings prepared via spray assembly can be tuned by adjusting the $\mathrm{pH}$, solvent, ionic strength, and/or precursor molar ratio and concentration. 


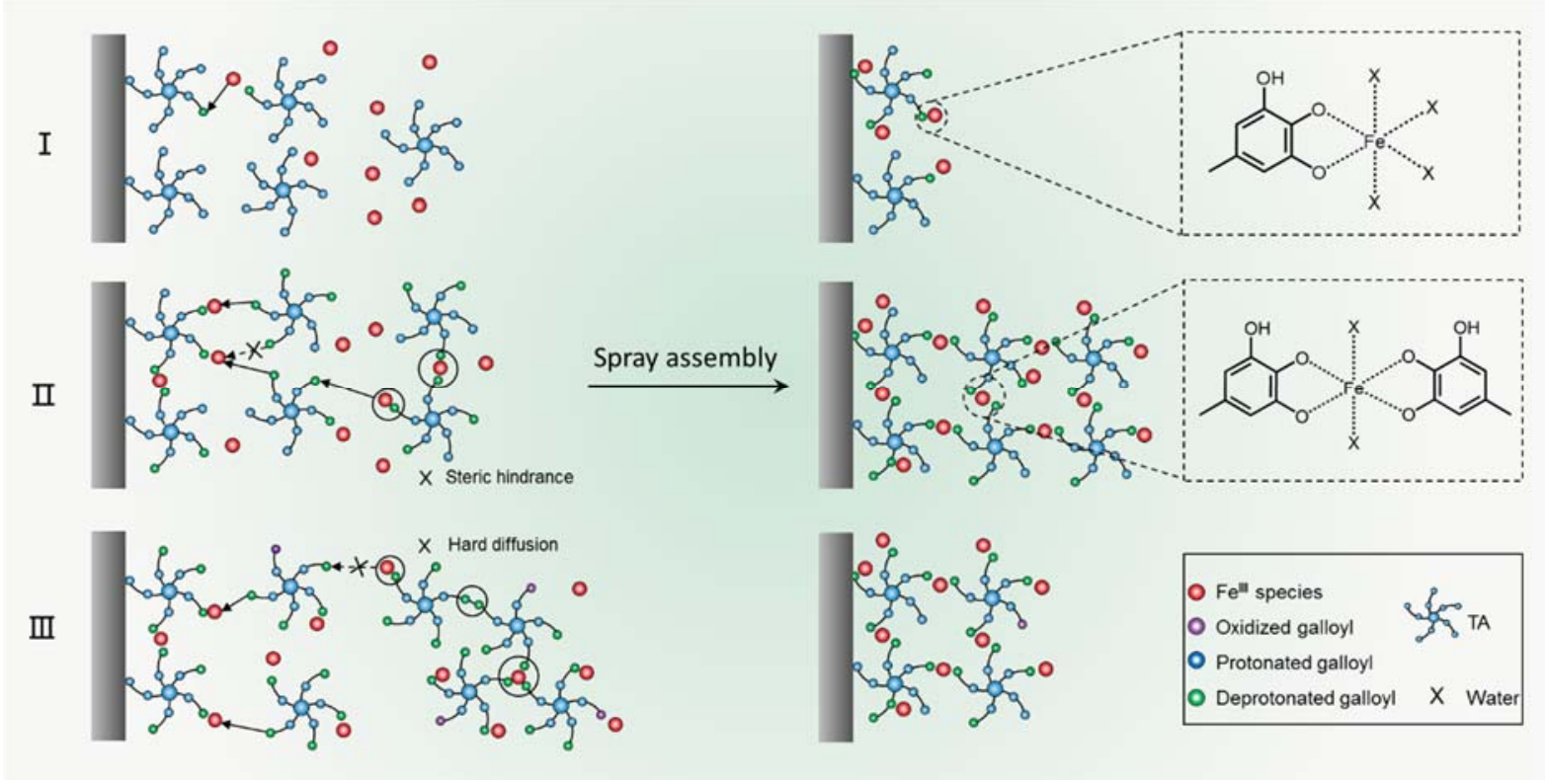

Scheme 1. Illustration of the proposed assembly process of TA-Fe $\mathrm{e}^{\mathrm{III}}$ networks prepared via spray assembly.

Spray Assembly of Patterned MPN coatings. Compared with immersive coating deposition, ${ }^{41}$ spray coating allows for the rapid patterning of large areas. ${ }^{42-44}$ However, many of these substrates are hydrophobic in nature and require the use of organic solutions for efficient coating. Therefore, we used ethanol as solvent to coat hydrophobic surfaces (e.g., natural rubber and polypropylene) with TA-Fe ${ }^{\mathrm{III}}$. For example, a gradient coating was fabricated by using a moveable cover on the surface of a yellow natural rubber sheet (Figure 3a). After 5 spray cycles, the cover above the substrate was moved $2 \mathrm{~cm}$ away from the right end of the substrate. Finally, the rubber substrate showed a change in color gradient from yellow to dark yellow to black from the left to the right ends of the substrate (Figure 3b), suggesting an increase in thickness from the left to right ends of the substrate. The increase in thickness was confirmed by the UV-vis absorbance spectra of the gradient coatings, which are shown in Figure S17. Furthermore, the wettability of the resulting coated rubber substrate changed from hydrophobic to hydrophilic with an increase in the TA-Fe ${ }^{\mathrm{III}}$ spray cycle number. The contact angles correspondingly changed from $140 \pm 5^{\circ}$ at the $1-\mathrm{cm}$ mark to $59 \pm 5^{\circ}$ at the 
9-cm mark (Figure 3c). The gradient MPN coatings could potentially serve as a versatile platform for secondary surface-mediated reactions, for example the synthesis of metal nanoparticles with a density gradient. ${ }^{45}$

Spray assembly was also exploited to control wettability on porous substrates. Uncoated polypropylene (PP) membranes were white and hydrophobic, with water contact angles of $135^{\circ}$ (Figure $3 \mathrm{f}$ and $\mathrm{g}$ ). After coating the front side of the PP membrane with 20 spray cycles, the membrane turned blue-black (Figure 3d) and superhydrophilic, with a water contact angle of $<10^{\circ}$ (Figure 3e). The reverse side of the membrane remained white and displayed the same water contact angle of $135^{\circ}$. FTIR spectra measurements confirmed the fabrication of Janus membranes; the absorbance at $1720 \mathrm{~cm}^{-1}$ was due to the TA molecules in the coatings (Figure S18). ${ }^{46}$ The dual wettability (hydrophilicity/hydrophobicity) of the TA-Fe ${ }^{\mathrm{III}}$ Janus membranes make them promising materials for droplet gating and moisture collection. ${ }^{47}$
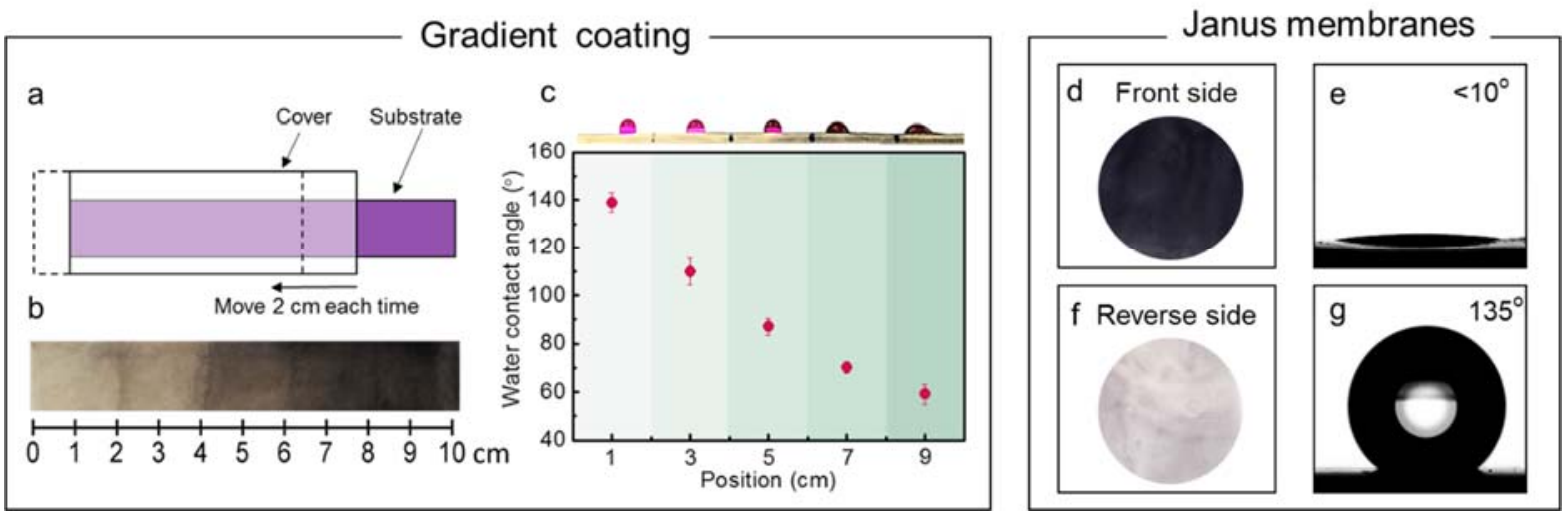

Figure 3. Patterned MPN coatings. Gradient coatings: (a) schematic illustration of the preparation of a gradient coating on natural rubber; (b) photograph of the natural rubber sheet after gradient spray coating; and (c) plot of the water contact angle as a function of spray coating position and corresponding images of water droplets (dyed red) on the gradient coating surface. Janus membranes: (d) front and (f) reverse sides of PP membranes ( $5 \mathrm{~cm}$ in diameter) after TA-Fe ${ }^{\mathrm{III}}$ spray coating, and the corresponding water contact angles (e) and (g). 
Oil-Water Separation and UV Shielding. To illustrate the potential applications of the spray-assembled MPN coatings, superhydrophilic membranes were prepared for oil-water separation and colorless coatings were prepared for UV shielding. Figure 4a shows that after spraying the PP membrane with TA and $\mathrm{Fe}^{\mathrm{III}}$ solutions on both sides, the membrane became superhydrophilic and superoleophobic underwater, with an oil contact angle of $\sim 153^{\circ}$, suggesting the potential of the membrane for oil-water separation. Figure $4 \mathrm{~b}$ demonstrates that water (dyed blue) permeates through the membranes, while $n$-hexane (dyed red) is isolated above the membrane. The separation efficiencies for different immiscible oil/water mixtures are shown in Figure 4c; the results indicated that $n$-hexane, toluene, and petroleum ether could successfully be separated by the superhydrophilic membrane, with separation efficiencies above $99 \%$, as determined by UV-vis analysis.
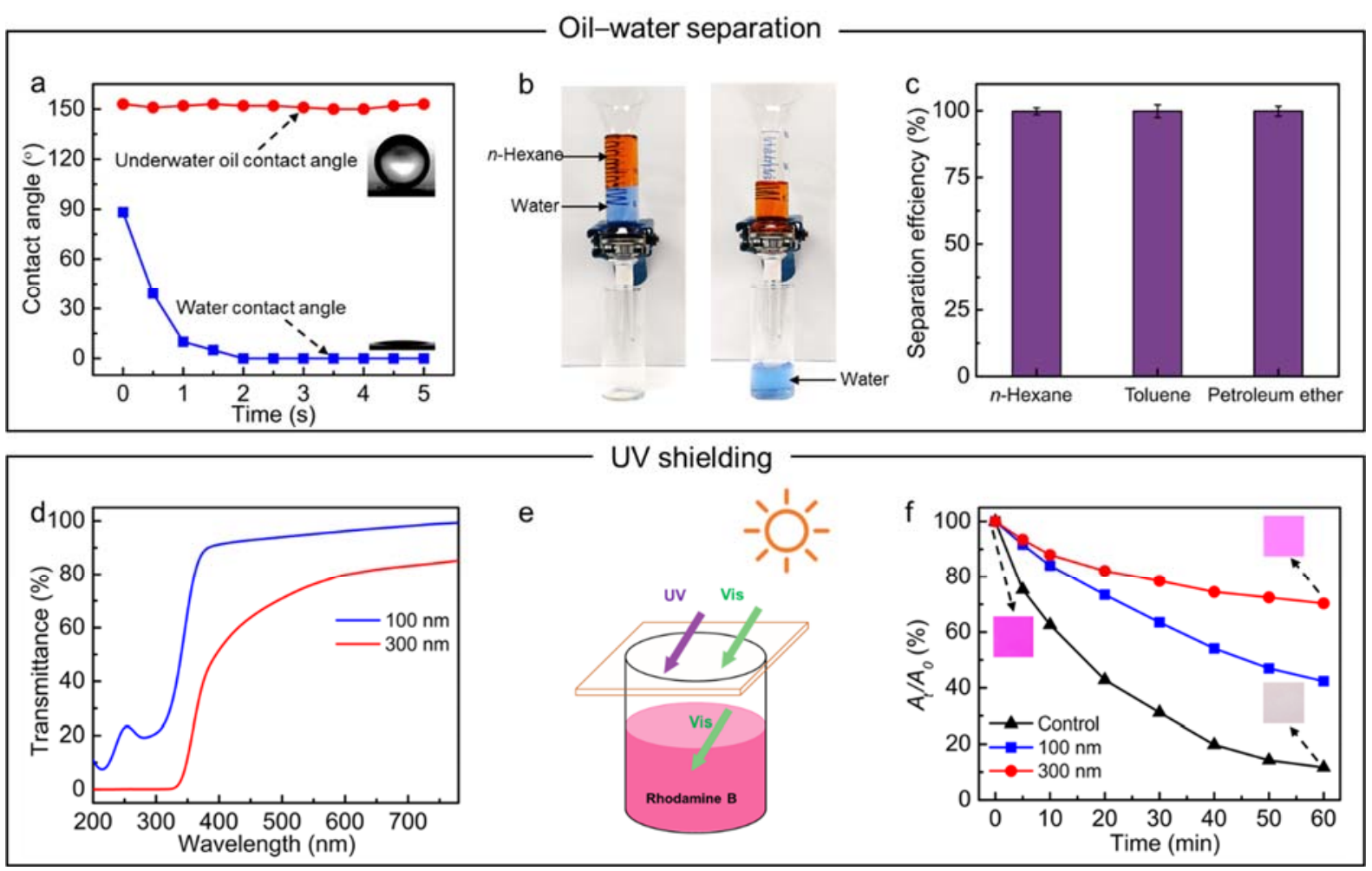

Figure 4. Applications of MPN coatings. Oil-water separation: (a) water contact angle and underwater oil contact angle of superhydrophilic PP membranes coated with TA-Fe ${ }^{\mathrm{III}}$ via spray assembly; (b) oil-water separation setup incorporating the superhydrophilic PP membrane; and 
(c) separation efficiency of different oil/water mixtures. UV shielding: (d) UV-vis light transmittance spectra of $\mathrm{TA}-\mathrm{Zr}^{\mathrm{IV}}$ coatings of different thicknesses $(100$ and $300 \mathrm{~nm})$; (e) schematic illustration of the UV-shielding property of MPN coating (a solution of Rh B is protected by the $\mathrm{TA}-\mathrm{Zr}^{\mathrm{IV}}$ coating); and (f) photodegradation of rhodamine $\mathrm{B}(\mathrm{Rh} \mathrm{B})$ solution protected by $\mathrm{TA}-\mathrm{Zr}^{\mathrm{IV}}$ coating with different thicknesses. A0, initial absorbance of $\mathrm{Rh} \mathrm{B}$ solution; $A_{t}$, absorbance of $\mathrm{Rh} \mathrm{B}$ solution at time $t$ (min). Insets show the color of the $\mathrm{Rh} \mathrm{B}$ solution at different degradation times. The control degradation experiment was performed in the absence of the coating.

Finally, the UV-shielding capability of the spray-assembled MPN coatings is demonstrated. $\mathrm{TA}-\mathrm{Zr}^{\mathrm{IV}}$ coatings were relatively colorless (Figure S19), showing more than $70 \%$ transmittance at $550 \mathrm{~nm}$ even at a film thickness of $\sim 300 \mathrm{~nm}$. However, these coatings could block UV light below $320 \mathrm{~nm}$ (Figure 4d) owing to the presence of the multiple aromatic rings of TA. ${ }^{48}$ The UV-shielding property of the $\mathrm{TA}-\mathrm{Zr}^{\mathrm{IV}}$ coatings was evaluated by the photocatalytic degradation of $\mathrm{Rh} \mathrm{B}$ in the presence of $\mathrm{TiO}_{2}$ nanoparticles. ${ }^{49-51}$ Under direct exposure of UV light, more than $90 \%$ of Rh B degraded within 60 min (Figure 4f, black curve). In contrast, using a TA$\mathrm{Zr}^{\mathrm{IV}}$-coated substrate (thickness of $\sim 300 \mathrm{~nm}$ ) as a protective shield (schematically shown in Figure 4e) greatly reduced the degradation of $\mathrm{Rh} B$ - only $\sim 25 \%$ degraded after 60 min. Although the above two applications were performed on a laboratory scale, the facile scaleup of the spray assembly process suggests that spray-assembled MPN coatings could find promising use for environmental applications. ${ }^{52}$

\section{CONCLUSIONS}

Spray assembly was investigated toward the engineering of functional MPN coatings using diverse phenolic ligands and transition metal ions. The effects of different assembly parameters such as $\mathrm{pH}$, solvent, ligand-to-metal molar ratio, and precursor concentration on the physicochemical properties of the resulting coatings including the thickness, roughness, and 
dominant coordination states were determined. Bis complexes appeared to be dominant in the films, and conditions favoring the bis state led to thicker films. To demonstrate the potential applications of the present method, superhydrophilic TA-Fe ${ }^{\mathrm{III}}$ and colorless $\mathrm{TA}-\mathrm{Zr}^{\mathrm{IV}}$ coatings were prepared for high efficiency oil-water separation and UV shielding, respectively. Moreover, considering the ease of use and versatility in incorporating different phenolic ligands and metals, the spray assembly method presented herein may also be applicable for constructing metal-organic framework thin films in the future. ${ }^{53,54}$ The present work not only demonstrates spray assembly as a facile and universal method to form homogeneous and patterned MPN coatings for different applications, but also provides new insights into the chemistry of metal-phenolic interfacial assembly.

\section{ASSOCIATED CONTENT}

Supporting Information. This material is available free of charge via the Internet at http://pubs.acs.org. Additional AFM analysis, XPS data, EDX mapping images, UV-vis absorption spectroscopy, DLS analysis, and FTIR spectra.

\section{AUTHOR INFORMATION}

\section{Corresponding Author}

*Email: fcaruso@unimelb.edu.au

\section{Notes}

The authors declare no competing financial interest.

\section{ACKNOWLEDGMENT}

This research was conducted and funded by the Australian Research Council Centre of Excellence in Convergent Bio-Nano Science and Technology (project number CE140100036) and by the ARC through the Discovery Project Scheme (DP170103331). F.C. acknowledges 
the award of a National Health and Medical Research Council (NHMRC) Senior Principal Research Fellowship (APP1135806).

\section{REFERENCES}

(1) Richardson, J. J.; Björnmalm, M.; Caruso, F. Technology-Driven Layer-by-Layer Assembly of Nanofilms. Science 2015, 348, 411.

(2) Xiao, F.-X.; Pagliaro, M.; Xu, Y.-J.; Liu, B. Layer-by-Layer Assembly of Versatile Nanoarchitectures with Diverse Dimensionality: A New Perspective for Rational Construction of Multilayer Assemblies. Chem. Soc. Rev. 2016, 45, 3088-3121.

(3) Lee, H.; Dellatore, S. M.; Miller, W. M.; Messersmith, P. B. Mussel-Inspired Surface Chemistry for Multifunctional Coatings. Science 2007, 318, 426-430.

(4) Zhuang, J.-L.; Terfort, A.; Wöll, C. Formation of Oriented and Patterned Films of MetalOrganic Frameworks by Liquid Phase Epitaxy: A Review. Coord. Chem. Rev. 2016, 307, 391424.

(5) Ejima, H.; Richardson, J. J.; Caruso, F. Metal-Phenolic Networks as a Versatile Platform to Engineer Nanomaterials and Biointerfaces. Nano Today 2017, 12, 136-148.

(6) Wei, Q.; Haag, R. Universal Polymer Coatings and Their Representative Biomedical Applications. Mater. Horiz. 2015, 2, 567-577.

(7) Ejima, H.; Richardson, J. J.; Liang, K.; Best, J. P.; van Koeverden, M. P.; Such, G. K.; Cui, J.; Caruso, F. One-Step Assembly of Coordination Complexes for Versatile Film and Particle Engineering. Science 2013, 341, 154-157.

(8) Guo, J.; Tardy, B. L.; Christofferson, A. J.; Dai, Y.; Richardson, J. J.; Zhu, W.; Hu, M.; Ju, Y.; Cui, J.; Dagastine, R. R.; Yarovsky, I.; Caruso, F. Modular Assembly of Superstructures from Polyphenol-Functionalized Building Blocks. Nat. Nanotechnol. 2016, 11, 1105-1111.

(9) Guo, J.; Ping, Y.; Ejima, H.; Alt, K.; Meissner, M.; Richardson, J. J.; Yan, Y.; Peter, K.; von Elverfeldt, D.; Hagemeyer, C. E.; Caruso, F. Engineering Multifunctional Capsules 
through the Assembly of Metal-Phenolic Networks. Angew. Chem., Int. Ed. 2014, 53, 55465551.

(10) Dai, Y.; Cheng, S.; Wang, Z.; Zhang, R.; Yang, Z.; Wang, J.; Yung, B. C.; Wang, Z.; Jacobson, O.; Xu, C.; Ni, Q.; Yu, G.; Zhou, Z.; Chen, X. Hypochlorous Acid Promoted Platinum Drug Chemotherapy by Myeloperoxidase-Encapsulated Therapeutic Metal Phenolic Nanoparticles. ACS Nano 2018, 12, 455-463.

(11) Shen, G.; Xing, R.; Zhang, N.; Chen, C.; Ma, G.; Yan, X. Interfacial Cohesion and Assembly of Bioadhesive Molecules for Design of Long-Term Stable Hydrophobic Nanodrugs toward Effective Anticancer Therapy. ACS Nano 2016, 10, 5720-5729.

(12) Li, D.; Shen, H.; Cai, C.; Sun, T.; Zhao, Y.; Chen, L.; Zhao, N.; Xu, J. Fabrication of Conductive Silver Microtubes Using Natural Catkin as a Template. ACS Omega 2017, 2, 1738 1745.

(13) Xiao, G.; Chen, W.; Tian, F.; Richardson, J. J.; Tardy, B. L.; Liu, M.; Joshi, N. S.; Guo, J. Thermal Transition of Bimetallic Metal-Phenolic Networks to Biomass-Derived Hierarchically Porous Nanofibers. Chem. Asian J. 2018, 13, 972-976.

(14) Rahim, M. A.; Ejima, H.; Cho, K. L.; Kempe, K.; Müllner, M.; Best, J. P.; Caruso, F. Coordination-Driven Multistep Assembly of Metal-Polyphenol Films and Capsules. Chem. Mater. 2014, 26, 1645-1653.

(15) Rahim, M. A.; Bjornmalm, M.; Bertleff-Zieschang, N.; Besford, Q.; Mettu, S.; Suma, T.; Faria, M.; Caruso, F. Rust-Mediated Continuous Assembly of Metal-Phenolic Networks. Adv. Mater. 2017, 29, 1606717.

(16) Kim, B. J.; Han, S.; Lee, K. B.; Choi, I. S. Biphasic Supramolecular Self-Assembly of Ferric Ions and Tannic Acid across Interfaces for Nanofilm Formation. Adv. Mater. 2017, 29, 1700784. 
(17) Maerten, C.; Lopez, L.; Lupattelli, P.; Rydzek, G.; Pronkin, S.; Schaaf, P.; Jierry, L.; Boulmedais, F. Electrotriggered Confined Self-Assembly of Metal-Polyphenol Nanocoatings Using a Morphogenic Approach. Chem. Mater. 2017, 29, 9668-9679.

(18) Schlaich, C.; Li, M.; Cheng, C.; Donskyi, I. S.; Yu, L.; Song, G.; Osorio, E.; Wei, Q.; Haag, R. Mussel-Inspired Polymer-Based Universal Spray Coating for Surface Modification: Fast Fabrication of Antibacterial and Superhydrophobic Surface Coatings. Adv. Mater. Interfaces 2018, 5, 1701254.

(19) Hong, S. H.; Hong, S.; Ryou, M. H.; Choi, J. W.; Kang, S. M.; Lee, H. Sprayable Ultrafast Polydopamine Surface Modifications. Adv. Mater. Interfaces 2016, 3, 1500857.

(20) Yun, G.; Pan, S.; Wang, T. Y.; Guo, J.; Richardson, J. J.; Caruso, F. Synthesis of Metal Nanoparticles in Metal-Phenolic Networks: Catalytic and Antimicrobial Applications of Coated Textiles. Adv. Healthcare Mater. 2017, 7, 1700934.

(21) Dierendonck, M.; De Koker, S.; De Rycke, R.; De Geest, B. G. Just Spray It - LbL Assembly Enters a New Age. Soft Matter 2014, 10, 804-807.

(22) Li, Y.; Wang, X.; Sun, J. Layer-by-Layer Assembly for Rapid Fabrication of Thick Polymeric Films. Chem. Soc. Rev. 2012, 41, 5998-6009.

(23) Ariga, K.; Yamauchi, Y.; Rydzek, G.; Ji, Q.; Yonamine, Y.; Wu, K. C.-W.; Hill, J. P. Layer-by-Layer Nanoarchitectonics: Invention, Innovation, and Evolution. Chem. Lett. 2014, $43,36-68$.

(24) Park, J.; Choi, S.; Moon, H.; Seo, H.; Kim, J.; Hong, S. P.; Lee, B.; Kang, E.; Lee, J.; Ryu, D.; Choi, I. S. Antimicrobial Spray Nanocoating of Supramolecular Fe(III)-Tannic Acid MetalOrganic Coordination Complex: Applications to Shoe Insoles and Fruits. Sci. Rep. 2017, 7, 6980. 
(25) Rahim, M. A.; Björnmalm, M.; Bertleff-Zieschang, N.; Ju, Y.; Mettu, S.; Leeming, M. G.; Caruso, F. Multiligand Metal-Phenolic Assembly from Green Tea Infusions. ACS Appl. Mater. Interfaces 2018, 10, 7632-7639.

(26) Rahim, M. A.; Kempe, K.; Müllner, M.; Ejima, H.; Ju, Y.; van Koeverden, M. P.; Suma, T.; Braunger, J. A.; Leeming, M. G.; Abrahams, B. F.; Caruso, F. Surface-Confined Amorphous Films from Metal-Coordinated Simple Phenolic Ligands. Chem. Mater. 2015, 27, $5825-5832$.

(27) Xu, Z.; Wang, X.; Liu, X.; Cui, Z.; Yang, X.; Yeung, K. W. K.; Chung, J. C.; Chu, P. K.; $\mathrm{Wu}$, S. Tannic Acid/ $\mathrm{Fe}^{3+} / \mathrm{Ag}$ Nanofilm Exhibiting Superior Photodynamic and Physical Antibacterial Activity. ACS Appl. Mater. Interfaces 2017, 9, 39657-39671.

(28) Zeng, T.; Zhang, X.; Guo, Y.; Niu, H.; Cai, Y. Enhanced Catalytic Application of Au@ Polyphenol-Metal Nanocomposites Synthesized by a Facile and Green Method. J. Mater. Chem. A 2014, 2, 14807-14811.

(29) Bertleff-Zieschang, N.; Rahim, M. A.; Ju, Y.; Braunger, J. A.; Suma, T.; Dai, Y.; Pan, S.; Cavalieri, F.; Caruso, F. Biofunctional Metal-Phenolic Films from Dietary Flavonoids. Chem. Commun. 2017, 53, 1068-1071.

(30) Björnmalm, M.; Cui, J.; Bertleff-Zieschang, N.; Song, D.; Faria, M.; Rahim, M. A.; Caruso, F. Nanoengineering Particles through Template Assembly. Chem. Mater. 2016, 29, 289-306.

(31) Oh, J. Y.; Jung, Y.; Cho, Y. S.; Choi, J.; Youk, J. H.; Fechler, N.; Yang, S. J.; Park, C. R. Metal-Phenolic Carbon Nanocomposites for Robust and Flexible Energy-Storage Devices. ChemSusChem 2017, 10, 1675-1682.

(32) Krogsgaard, M.; Andersen, A.; Birkedal, H. Gels and Threads: Mussel-Inspired One-Pot Route to Advanced Responsive Materials. Chem. Commun. 2014, 50, 13278-13281. 
(33) Holten-Andersen, N.; Harrington, M. J.; Birkedal, H.; Lee, B. P.; Messersmith, P. B.; Lee, K. Y.; Waite, J. H. pH-Induced Metal-Ligand Cross-Links Inspired by Mussel Yield SelfHealing Polymer Networks with Near-Covalent Elastic Moduli. Proc. Natl. Acad. Sci. U. S. A. 2011, 108, 2651-2655.

(34) Sileika, T. S.; Barrett, D. G.; Zhang, R.; Lau, K. H. A.; Messersmith, P. B. Colorless Multifunctional Coatings Inspired by Polyphenols Found in Tea, Chocolate, and Wine. Angew. Chem., Int. Ed. 2013, 52, 10766-10770.

(35) Yu, J.; Wei, W.; Danner, E.; Ashley, R. K.; Israelachvili, J. N.; Waite, J. H. Mussel Protein Adhesion Depends on Interprotein Thiol-Mediated Redox Modulation. Nat. Chem. Biol. 2011, 7, 588-590.

(36) Lee, H.; Scherer, N. F.; Messersmith, P. B. Single-Molecule Mechanics of Mussel Adhesion. Proc. Natl. Acad. Sci. U. S. A. 2006, 103, 12999-13003.

(37) Wei, W.; Yu, J.; Broomell, C.; Israelachvili, J. N.; Waite, J. H. Hydrophobic Enhancement of Dopa-Mediated Adhesion in a Mussel Foot Protein. J. Am. Chem. Soc. 2012, 135, 377-383. (38) Krogsgaard, M.; Hansen, M. R.; Birkedal, H. Metals \& Polymers in the Mix: Fine-Tuning the Mechanical Properties \& Color of Self-Healing Mussel-Inspired Hydrogels. J. Mater. Chem. B 2014, 2, 8292-8297.

(39) Xu, H.; Nishida, J.; Ma, W.; Wu, H.; Kobayashi, M.; Otsuka, H.; Takahara, A. Competition between Oxidation and Coordination in Cross-Linking of Polystyrene Copolymer Containing Catechol Groups. ACS Macro Lett. 2012, 1, 457-460.

(40) Guo, J.; Richardson, J. J.; Besford, Q. A.; Christofferson, A. J.; Dai, Y.; Ong, C. W.; Tardy, B. L.; Liang, K.; Choi, G. H.; Cui, J.; Yoo, P. J.; Yarovsky, I.; Caruso, F. Influence of Ionic Strength on the Deposition of Metal-Phenolic Networks. Langmuir 2017, 33, 1061610622. 
(41) Zhao, M.-X.; Li, J.; Gao, X. Gradient Coating of Polydopamine via CDR. Langmuir 2017, $33,6727-6731$.

(42) Morton, S. W.; Herlihy, K. P.; Shopsowitz, K. E.; Deng, Z. J.; Chu, K. S.; Bowerman, C. J.; Desimone, J. M.; Hammond, P. T. Scalable Manufacture of Built-to-Order Nanomedicine: Spray-Assisted Layer-by-Layer Functionalization of PRINT Nanoparticles. Adv. Mater. 2013, $25,4707-4713$.

(43) Lefort, M.; Popa, G.; Seyrek, E.; Szamocki, R.; Felix, O.; Hemmerle, J.; Vidal, L.; Voegel, J. C.; Boulmedais, F.; Decher, G.; Schaaf, P. Spray-on Organic/Inorganic Films: A General Method for the Formation of Functional Nano- to Microscale Coatings. Angew. Chem., Int. Ed. 2010, 49, 10110-10113.

(44) Krogman, K. C.; Lowery, J. L.; Zacharia, N. S.; Rutledge, G. C.; Hammond, P. T. Spraying Asymmetry into Functional Membranes Layer-by-Layer. Nat. Mater. 2009, 8, 512-518.

(45) Goreham, R. V.; Short, R. D.; Vasilev, K. Method for the Generation of Surface-Bound Nanoparticle Density Gradients. J. Phys. Chem. C 2011, 115, 3429-3433.

(46) Zhang, Y.; Su, Y.; Peng, J.; Zhao, X.; Liu, J.; Zhao, J.; Jiang, Z. Composite Nanofiltration Membranes Prepared by Interfacial Polymerization with Natural Material Tannic Acid and Trimesoyl Chloride. J. Membr. Sci. 2013, 429, 235-242.

(47) Yang, H. C.; Hou, J.; Chen, V.; Xu, Z. K. Janus Membranes: Exploring Duality for Advanced Separation. Angew. Chem., Int. Ed. 2016, 55, 13398-13407.

(48) Shutava, T.; Prouty, M.; Kommireddy, D.; Lvov, Y. pH Responsive Decomposable Layerby-Layer Nanofilms and Capsules on the Basis of Tannic Acid. Macromolecules 2005, 38, $2850-2858$.

(49) Wang, Y.; Su, J.; Li, T.; Ma, P.; Bai, H.; Xie, Y.; Chen, M.; Dong, W. A Novel UVShielding and Transparent Polymer Film: When Bioinspired Dopamine-Melanin Hollow Nanoparticles Join Polymers. ACS Appl. Mater. Interfaces 2017, 9, 36281-36289. 
(50) Zaccariello, G.; Back, M.; Zanello, M.; Canton, P.; Cattaruzza, E.; Riello, P.; Alimonti, A.; Benedetti, A. Formation and Controlled Growth of Bismuth Titanate Phases into Mesoporous Silica Nanoparticles: An Efficient Self-Sealing Nanosystem for UV Filtering in Cosmetic Formulation. ACS Appl. Mater. Interfaces 2017, 9, 1913-1921.

(51) Tu, Y.; Zhou, L.; Jin, Y. Z.; Gao, C.; Ye, Z. Z.; Yang, Y. F.; Wang, Q. L. Transparent and Flexible Thin Films of ZnO-Polystyrene Nanocomposite for UV-Shielding Applications. $J$. Mater. Chem. 2010, 20, 1594-1599.

(52) Zhu, J.; Huang, A.; Ma, H.; Ma, Y.; Tong, K.; Ji, S.; Bao, S.; Cao, X.; Jin, P. Composite Film of Vanadium Dioxide Nanoparticles and Ionic Liquid-Nickel-Chlorine Complexes with Excellent Visible Thermochromic Performance. ACS Appl. Mater. Interfaces 2016, 8, 2974229748.

(53) Sakamoto, R. Bottom-up Creation of Functional Low-Dimensional Materials Based on Metal Complexes. Bull. Chem. Soc. Jpn. 2017, 90, 272-278.

(54) Shekhah, O.; Liu, J.; Fischer, R. A.; Wöll, Ch. MOF Thin Films: Existing and Future Applications. Chem. Soc. Rev. 2011, 40, 1081-1106. 
Table of Contents Graphic

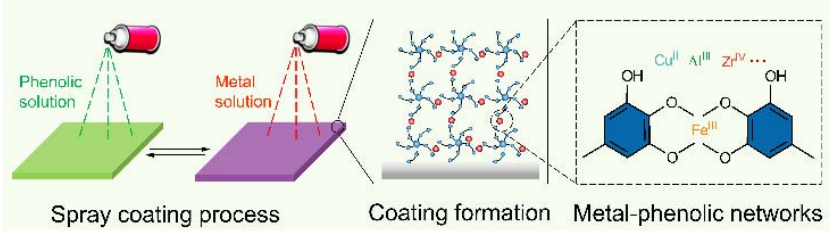

